\title{
Memória, Informação e Pós-verdade em tempos líquidos
}

\author{
Memory, Information and Post-truth in net time \\ Memoria, Información y Post-verdad en tiempos \\ netos
}

Maytê Luanna Dias de MELO ${ }^{1}$

Maria Nilza Barbosa ROSA²

Bernardina Maria Juvenal

Freire de OLIVEIRA ${ }^{3}$

\section{Correspondência}

Autor para correspondência: Maytê Luanna Dias de Melo.

Endereço completo: Rua General Canrobert, 73, apt. 102, Catolé. Campina Grande, Paraíba,

Brasil. CEP: 58410435.

E-mail: lumeloo@yahoo.com.br

ORCID: https://orcid.org/0000-0002-7310-2572

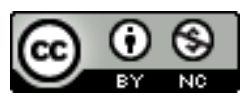

Submetido em: $15 / 03 / 2020$

Aceito em: 08/05/2020

Publicado em: 10/06/2020

1 Doutoranda e Mestra em Ciência da Informação pela Universidade Federal da Paraíba.

2 Doutora em Letras e Mestra em Ciência da Informação pela Universidade Federal da Paraíba.

3 Doutora em Letras e Mestra em Ciência da Informação pela Universidade Federal da Paraíba. Professora Associado da Universidade Federal da Paraíba. Presidente da Academia Feminina de Letras e Artes da Paraíba; Membro do Instituto Histórico e Geográfico de Areia. Vice-Reitora da Universidade Federal da Paraíba. 


\title{
RESUMO
}

Analisando as mudanças socioculturais na sociedade através da ótica Baumaniana e correlacionando essas mudanças ao papel que a memória exerce, como constituinte do processo dos discursos, e, aos novos fenômenos de disseminação de pós-verdades, este ensaio tem como objetivo refletir o uso da memória coletiva para a ideação de pósverdades, utilizando-se de características sociopolíticas de tempos líquidos apontadas por Bauman (2007). As reflexões emanam dos estudos e discussões sobre memória, especialmente, memória coletiva; da dinâmica das relações nas redes sociais, de onde partem a disseminação e o compartilhamento de pós-verdades; e da informação como elemento constituinte de emancipação da sociedade. As várias facetas desveladas sobre o tema apontam para as particularidades com que estas questões se apresentam para cada indivíduo, a partir de sua construção histórica, suas crenças e suas possibilidades. O presente trabalho foi realizado com apoio da Coordenação de Aperfeiçoamento de Pessoal de Nível Superior Brasil (CAPES).

Palavras-chave: Informação. Memória. Pós-verdade. Redes Sociais. Sociedade.

\begin{abstract}
Analyzing how sociocultural changes in society through the Baumanian perspective and correlating these changes in the role that memory plays, as a component of the discourse process, and, for new episodes of dissemination of post-truths, this test aims to test or use memory collective for an idea of post-truths, using socio-political resources of times pointed out by Bauman (2007). As reflections emanate from studies and discussions about memory, especially collective memory; the skills of relationships in social networks, where they participate in the dissemination and sharing of post-truths; and information as a constituent element of the emancipation of society. As several facets developed on the theme point to particularities with these questions, they are presented to each individual, based on their historical construction, their beliefs and their possibilities. This study was financed in part by the Coordenação de Aperfeiçoamento de Pessoal de Nível Superior - Brasil (CAPES)
\end{abstract}

Keywords: Information. Memory. Post-truth. Social networks. Society.

\section{RESUMEN}

Analizando cómo los cambios socioculturales en la sociedad a través de la perspectiva de Baumanian y correlacionando estos cambios en el papel que juega la memoria, como un componente del proceso del discurso, y, para nuevos episodios de diseminación de verdades posteriores, esta prueba tiene como objetivo probar o usar la memoria colectiva para una idea de las verdades posteriores, utilizando recursos sociopolíticos de los tiempos señalados por Bauman (2007). Como reflexiones emanan de los estudios y debates sobre la memoria, especialmente la memoria colectiva; las habilidades de las relaciones en las redes sociales, donde participan en la difusión y el intercambio de verdades posteriores; e información como elemento constitutivo de la emancipación de la sociedad. Como varias facetas desarrolladas sobre el tema apuntan a particularidades con estas preguntas, se presentan a cada individuo, en función de su construcción histórica, sus creencias y sus posibilidades. Este trabajo se realizó con el apoyo de la Coordinación para la Mejora del Personal de Educación Superior Brasil (CAPES).

Palabras clave: Información. Memoria. Post-verdad. Redes sociales. Sociedad.

\section{INTRODUÇÃO}

É natural que os indivíduos de uma comunidade, nascidos em um mesmo contexto social, possuam memórias muito próximas sobre seu 
passado histórico-social. As brincadeiras, as músicas, os ídolos, os filmes, as novelas ou os seriados de TV, fazem parte de um conjunto de memórias coletivas que podem ser revocadas instantaneamente.

Unidos por vivências que vão além do contexto pessoal, esses aspectos denominam e diferem as gerações. $E$, mesmo que não tenham sido construídas memórias quanto a um dado período do tempo, a literatura, a formação escolar, e atualmente, as redes sociais, formulam uma ideia aproximada do que aconteceu em outras épocas da humanidade. Como exemplos, têm-se o holocausto, os bombardeamentos atômicos das cidades Hiroshima e Nagasaki, a ida do homem à lua, a chegada das caravelas em Pindorama, e diversos outros eventos que inquietam e revocam memórias coletivas. Para Halbwachs (1990), a memória coletiva desempenha um papel fundamental nos processos históricos. Ela dá vida aos objetos culturais, realça os momentos históricos significativos preservando o valor do passado para os grupos sociais, e, é a guardiã dos objetos culturais que atravessam os tempos e que, então, podem vir a se constituir fontes para a pesquisa histórica.

Portanto, este trabalho surge da necessidade de refletir em torno da conjuntura política e social pela qual estamos vivenciando atualmente, sob a ótica da memória, constituinte do processo dos discursos e da informação como arma no combate ao caos que a pós-verdade vem instaurando.

Para isso, a discussão parte da observação indireta dos discursos de ódio reverberados na sociedade, devido à descrença dos indivíduos quanto ao cenário político mundial que, por meio de fake news, fortalece um fenômeno de disseminação de informação de ordem difusa e/ou improcedente que somada à crença e apelo pessoais são propagadas, sobretudo, por meio das redes sociais.

As reflexões emanam dos estudos e discussões sobre memória, especialmente, memória coletiva, da dinâmica das relações nas redes sociais, de onde a disseminação das pós-verdades e da informação como elemento constituinte de emancipação da sociedade. 


\section{MEMÓRIA COLETIVA E PÓS-VERDADE}

Cardini (1988) considera que uma das grandes protagonistas da história é a memória coletiva. Para o autor ela tece e retece, continuamente, aquilo que o tempo cancela, e tende a transformar os fatos do passado em imagens e ideias sem rupturas, como se estabelecesse uma continuidade entre o que é passado e o que é presente, constituindo a unidade de tudo aquilo que, no processo histórico do grupo, representou quebra ou ruptura.

A memória é um trabalho do sujeito, mas sempre construída em grupo, nesse sentido Halbwachs (1990) entende que o indivíduo que lembra é um indivíduo inserido e habitado por grupos de referência. Para Schmidt e Mahfoud (1993, não paginado),

grupo de referência é um grupo do qual o indivíduo já fez parte e com o qual estabeleceu uma comunidade de pensamentos, identificou-se e confundiu seu passado. O grupo está presente para o indivíduo não necessariamente, ou mesmo fundamentalmente, pela sua presença física, mas pela possibilidade que $\mathrm{o}$ indivíduo tem de retomar os modos de pensamento e a experiência comum próprias do grupo. A vitalidade das relações sociais do grupo dá vitalidade às imagens, que constituem a lembrança. Portanto, a lembrança é sempre fruto de um processo coletivo e está sempre inserida num contexto social preciso.

Segundo os autores, os grupos de referência são grupos com os quais o indivíduo se identificou e tem possibilidade de retomar os modos de pensamento. Para eles, na memória coletiva, o passado é constantemente reconstruído e vivificado enquanto é (re)significado. Deste modo, a memória coletiva pode ser entendida como uma forma de "história vivente". A memória coletiva vive, sobretudo, na tradição, que é o quadro mais amplo onde seus conteúdos se atualizam e se articulam entre si, e os grupos de referência são essenciais (SCHMIDT; MAHFOUD, 1993).

Num contexto atual, onde a sociedade é percebida por meio de suas conexões e desconexões (BAUMAN, 2001), sobretudo, nas redes sociais, a memória coletiva pode ser observada quando são revocadas lembranças 
sobre determinada época, em postagens de perfis e/ou fanpages, de grupos, bem como, nos comentários acrescidos a eles. No entanto, ao mesmo passo em que as memórias coletivas revocam bons acontecimentos, elas podem também evocar eventos e fatos desumanos, vis e cruéis. E aqui se pode utilizar como exemplo, o período da ditadura militar no Brasil. De certa forma, os nostálgicos desse período são vítimas que foram massacradas por mentiras que, em sua ingenuidade, tomaramnas por verdades.

A memória coletiva nessa conjuntura de pós-verdade se insere como um artefato de contextualização de uma verdade. Deste modo, considerase pós-verdade a soma de memórias coletivas, de crenças pessoais e apelos emocionais que, independentes de estarem ou não contrárias a verdades fatídicas, são concebidas por determinado indivíduo.

A palavra "pós-verdade" foi eleita pelo Oxford Dictionaries, que é um departamento da Universidade de Oxford responsável pela elaboração de dicionários, como a palavra do ano 2018 e adjetiva algo,

relacionando-se ou denotando circunstâncias nas quais os fatos objetivos são menos influentes na formação da opinião pública do que os apelos à emoção e à crença pessoal. Nesta era da política pós-verdade, é fácil selecionar os dados e chegar a qualquer conclusão que você desejar.'Alguns comentaristas observaram que estamos vivendo uma era pós-verdade' (OXFORD DICTIONARIES, 2018, não paginado, tradução nossa).

É importante perceber a pós-verdade em debates e discussões nas redes sociais, onde ela se enquadra nos apelos emocionais, desassociando e ignorando as réplicas fáticas para dar ênfase às memórias e aos estereótipos discriminatórios. Ela resume-se à ideia de que algo que aparenta ser verdade é mais importante que a própria verdade em si. E, a verdade, segundo Foucault (2002), é regulada pela sociedade e desempenha um papel político e econômico. Deve-se entender como verdade "um conjunto de procedimentos regulados para a produção, a lei, a repartição, a circulação e o funcionamento dos enunciados" (FOUCAULT, 2002, p. 10). 
No ano de 1979, quando escreveu a Microfísica do Poder, o autor já sinalizava um combate em torno desse fenômeno, mais especificamente, em torno do que a verdade representa na e para a sociedade.

\begin{abstract}
Há um combate 'pela verdade' ou, ao menos, 'em torno da verdade' - entendendo-se, mais uma vez, que por verdade não quero dizer 'o conjunto das coisas verdadeiras a descobrir ou a fazer aceitar', mas o 'conjunto das regras segundo as quais se distingue o verdadeiro do falso e se atribui aos verdadeiros efeitos específicos de poder'; entendendo-se também que não se trata de um combate 'em favor' da verdade, mas em torno do estatuto da verdade e do papel econômico-político que ela desempenha. É preciso pensar os problemas políticos dos intelectuais não em termos de 'ciência/ideologia', mas em termos de 'verdade/poder'. $\mathrm{E}$ então que a questão da profissionalização do intelectual, da divisão entre trabalho manual e intelectual, pode ser novamente colocada (FOUCAULT, 2002, p. 11).
\end{abstract}

Para o autor, a verdade deve ser entendida e posicionada como um conjunto de regras que distingue o verdadeiro do falso e se atribui ao verdadeiro, efeitos específicos de poder. Portanto, quando se discute a pós-verdade, a memória e a informação na sociedade, o objetivo é tentar desvinculá-las do sistema de poder que também está circunscrito sobre elas. Como se elas viessem acompanhadas, e de fato vêm, de uma ideologia hegemônica excludente e de interesses bem definidos. Não refletir sobre as possíveis relações de causa/efeito que a pós-verdade pode apresentar na sociedade é o mesmo que aceitá-las, encobri-las e acobertá-las. E é o que se tem feito nas redes sociais. Segundo Dunker et al. (2017, p. 107):

a possibilidade de uma verdade em caixa alta, capaz de nos explicar o desconhecido, não vem mais ao caso. Contentamo-nos com pouco. E esse pouco é a pós-verdade. A verdade que podemos aceitar. A verdade que cola, a que vemos circular, a que podemos produzir publicitariamente, a que alimenta a mídia.

Para Dunker et al. (2017), a pós-verdade é um conceito que coloca em questão o fim da verdade como um valor maior. A ideia de pósverdade possibilita tratar de uma verdade útil, à mídia e ao mercado, uma verdade consumida e consumível. Então, a informação pode ser (e é) a peça chave para esse quebra-cabeça de elucubrações. Ela esclarece, 
clareia o percurso do entendimento desse jogo de interesses que subliminarmente pode instituir o caos na sociedade. Portanto, pode-se pensar que esse é um momento prolífero de refletir o papel das Ciências Sociais Aplicadas, sobretudo, da Ciência da Informação, enquanto protagonistas num embate entre a informação, o poder, a verdade e a pós-verdade.

\title{
3 VERDADE, PODER E INFORMAÇÃO NAS REDES SOCIAIS
}

A verdade é regulamentada pelo poder e cada sociedade tem seu regime de verdade, ou seja, os discursos que são acolhidos e tidos como verdadeiros. Para Foucault (2002), essa "política geral" de verdade é regulamentada por mecanismos e instâncias que distinguem os enunciados que são tidos/ditos como verdadeiros dos que são tidos/ditos como falsos.

\begin{abstract}
A verdade é deste mundo; ela é produzida nele graças a múltiplas coerções e nele produz efeitos regulamentados de poder. Cada sociedade tem seu regime de verdade, sua "política geral" de verdade: isto é, os tipos de discurso que ela acolhe e faz funcionar como verdadeiros; os mecanismos e as instâncias que permitem distinguir os enunciados verdadeiros dos falsos, a maneira como se sanciona uns e outros; as técnicas e os procedimentos que são valorizados para a obtenção da verdade; o estatuto daqueles que têm 0 encargo de dizer 0 que funciona como verdadeiro (FOUCAULT, 2002, p. 10).
\end{abstract}

Eis aqui um dos pontos que têm provocado a ascensão da pósverdade nos dias atuais: os discursos, sobretudo das redes sociais, que são acolhidos e tidos como regimes de verdade, e assim, seguem propagados pela sociedade. Sobre isso, Dunker et al. (2017, p. 109) declaram que:

Há muito tempo que se discute sobre as condições de invenção da verdade, aquilo que Foucault ao longo de sua vida chamou de episteme e que foi se desenvolvendo como uma espécie de estratégia, uma astúcia, que foi se estabelecendo como formas de "veridição", aquelas formações discursivas nas quais não é exatamente a verdade como um ideal que está em jogo, mas um regime da verdade no qual a verdade como ideia e coisa, a um só tempo, é manipulada. O regime da verdade é o regime de produção da crença, do real, do que consideramos certo e seguro, substancial e ontológico, ou melhor, do que deve ser percebido 
desse modo. E que é produzido por meios específicos de produção da comunicação, da informação e do discurso com esse objetivo.

Em se tratando de regime de verdade, daquilo que é produzido através da crença, do real considerado seguro, ou que deve ser considerado assim, e, "sendo a verdade uma categoria dos tempos dos atos de fala, quando descobrimos que falar é fazer alguma coisa" (DUNKER et al., 2017, p. 109), qual a qualidade do uso de nossa fala? Falamos a verdade? Quais consequências esse uso nos traz?

Um claro exemplo disso é o que se fala nas redes sociais sobre os acontecimentos históricos. Muitas pessoas têm memórias do que foram esses acontecimentos. Outras viveram à mesma época, mas em contextos completamente distintos. Há grupos de indivíduos que participaram de eventos específicos e, por fim, há aqueles que não experienciaram absolutamente nada do que é dito. Porém, esses ditos provêm da memória. E, memórias são memórias! Segundo Assmann (2011, p. 53), elas caminham "passado adentro por entre o véu do esquecimento". Para a autora, há um abismo entre presente e passado e assim foi iniciada a invenção da história nacional, "a construção de uma memória coletiva que se apresenta como busca do passado perdido nesse abismo" (ASSMANN, 2011, p. 59).

No período da ditadura militar, no Brasil, a maior parte dos fatos não era informada. O noticiário era produzido, naquela época, pela mídia dominante, manipulando as informações publicizadas a fim de que a opinião pública acreditasse na versão divulgada pelo regime militar, cujas ações eram coordenadas a partir de um núcleo central, o Serviço Nacional de Informações (SNI). Criado em 1964, esse órgão subordinou celeremente outros órgãos repressivos, como os centros de informações das três armas, a polícia federal e as polícias estaduais (MAGALHÃES, 1997).

O restante da mídia era submetido à censura e/ou possuía donos favoráveis à ditadura. Deste modo, a mídia construiu um falso Brasil sob os generais. Nessa época, também não havia o contraponto da internet e, 
consequentemente, dos usuários das redes sociais, o que dava à mídia corporativa o monopólio da informação que chegava ao público. Então, esse era o regime de verdade da época. $E$, em vista disso, até os dias de hoje, muitas pessoas reverberam informações nesse sentido, de que o período ditatorial foi um período sem violência nas ruas, sem crime e sem corrupção.

Compartilhar ideias e informações sobre a nova conjuntura sociopolítica brasileira faz perceber com clareza o fortalecimento de um movimento, outrora adormecido, em prol de um nacionalismo político de direita, que visa o retorno da intervenção militar no país. Numa busca rápida por entre as páginas das redes sociais dos brasileiros, é possível observar o crescente número de adeptos a discursos forjados sob a égide moralista. Esses discursos escondem e, às vezes, escancaram, um sentimento de autoridade e conservadorismo, discriminação e preconceito que encontram legitimidade devido ao número assustador de adeptos e defensores.

Normalmente, eles estão atrelados a partidos ou figuras públicas de políticos que têm angariado um expressivo número de seguidores que curtem, compartilham e, consequentemente, propagam o conteúdo de suas páginas sem ponderação. Tais páginas apresentam discursos moralistas contra homossexuais, posts que expressam preconceitos de origem e de classe, discursos racistas, machistas, misóginos, que defendem na maioria das vezes gritante, a volta da intervenção militar, e, ainda, popularizam informações dúbias e inverdades.

Essas páginas se utilizam do sentimento descrente do brasileiro sob a atual conjuntura política e usam do argumento de combate à corrupção, respeito à ordem, preservação dos valores, com discursos de ódio, apelo à emoção e as crenças sociais, e evocação da memória coletiva do período ditatorial, constantemente. Segundo Halbwachs (2013), nossa memória se apega mais ao fato vivido que a fatos pelos quais entramos em contato através dos livros, por exemplo. Então, a história não é vista como um elemento indispensável para o processo de preservação da memória. E, 
sobre a história, Halbwachs entende não como uma sucessão cronológica de acontecimentos, "mas tudo o que faz com que um período se distinga dos outros, do qual os livros e as narrativas em geral nos apresentam apenas um quadro muito esquemático e incompleto" (HALBWACHS, 2013, p. 79).

Nessa mesma linha, a memória é pensada como "uma reconstrução do passado com a ajuda de dados tomados de empréstimo ao presente e preparados por outras reconstruções feitas em épocas anteriores", da qual "a imagem de outrora já saiu bastante alterada" (HALBWACHS, 2013, p. 91). Portanto, todo o contexto no qual o indivíduo, neste caso, o usuário das redes sociais está envolto, contribui de alguma maneira para (re)construir os vestígios e impressões de um determinado momento.

Nesse contexto, as memórias coletivas de um determinado grupo de usuários unem-se às crenças pessoais e aos apelos emocionais, para disseminar pós-verdade e criar um espaço de segregação, antidemocrático e de comportamentos discriminatórios nas redes sociais, formando o que Elias (1994) nomeou em seu livro, Sociedade dos Indivíduos, "mentalidade grupal", uma psicologia social ou de massa, natural da sociedade.

\begin{abstract}
Às vezes, os membros deste último campo, mais ou menos como seus equivalentes nas ciências sociais ou históricas, atribuem a formações sociais inteiras, ou a uma massa de pessoas, uma alma própria que transcende as almas individuais, uma anima collectiva ou mentalidade grupal. E quando não chegam a ir tão longe, é comum se contentarem em tratar os fenômenos sócio-psicológicos como a soma ou o que dá na mesma a média das manifestações psicológicas de muitos indivíduos (ELIAS, 1994, p.15).
\end{abstract}

Para o autor, a dicotomia entre sociedade e indivíduo fica em evidência, pois não é possível compreender a sociedade, sua história e o curso que segue sem que se compreenda "de que modo um grande número de indivíduos compõem entre si algo maior e diferente de uma coleção de indivíduos isolados" (ELIAS, 1994, p. 16). 


\section{PÓS-VERDADE E SOCIEDADE LÍQUIDA}

Não há como falar em sociedade, atualmente, sem estabelecer relação direta com Bauman, um dos mais importantes sociólogos contemporâneos que afirma ser a principal característica dos novos tempos, a liquidez. A liquidez a que Bauman $(2001$; 2007) se refere é uma característica na qual as experiências e relações são marcadas pela efemeridade, pelo caráter fluido e dispersivo, como um fluxo de água, sem pretensão de solidez, que não assume forma alguma por si mesma, ou que assume todas as formas que forem impostas. Portanto, na passagem da fase sólida da modernidade para a fase líquida, as organizações sociais não se mantêm por muito tempo, pois se decompõem e se dissolvem muito rápido, e o autor configura o medo como um fator preponderante dessa sociedade líquido-moderna globalizada.

Esse medo generalizado tem se intensificado através da abertura do comércio e do capital, onde o Estado perdeu forças para o mercado e deixou de exercer, de forma competente, suas funções, sobretudo a segurança. Desse modo, as funções do Estado são terceirizadas e a iniciativa privada é vista como o playground para as forças do mercado. Devido a isso, a sociedade se vê impotente, em um campo de batalha, e não encontra caminhos seguros para seguir, aumentando a individualização. Então, a individualização afrouxa os laços, e os laços naturais dão lugar aos laços artificiais, consequentemente provisórios, gerando um declínio na solidariedade e aumento das incertezas e da vigilância (BAUMAN, 2007).

Os laços naturais são muito bem representados pela família. São laços que não se pode escolher, estão pré-determinados, são involuntários. Porém, os laços artificiais são escolhidos, podem ser representados por grupos que possuam características semelhantes, e isso faz com que se tenha mais proximidade de ideias e pensamentos, que os próprios laços naturais, como por exemplo, sindicatos, grupos 
feministas; grupos em defesa dos negros; grupos nacionalistas; grupos LGBTQIA+, entre outros.

Bauman (2007) assegura que o planeta está atravessado por autoestradas da informação, nas quais as mazelas vividas estão sob um click dentro de nossas casas, aumentando a insegurança existencial e disseminação de temores de perigos generalizados. Dessa forma, cresce o apelo à segurança de modo a incentivar os indivíduos a defenderem a intervenção militar, baseados no entendimento de que esse período foi um período sem violência, onde as pessoas sentiam-se seguras e protegidas. Somado ao progresso da globalização liberal, avançam o nacionalismo, o fascismo religioso e o terrorismo, tornando o mercado sem fronteira uma receita para a injustiça e a desordem mundial, consequentemente 0 medo.

O principal ponto a ser discutido, quanto ao surgimento e/ou permanência do medo nas sociedades líquidas, não é o medo em si, mas em que esse medo pode se desdobrar, como por exemplo, a busca por casas de muros altos, smartphones que possuam tecnologias antifurto, carros blindados, porretes, revólveres; a população busca frequentar aulas de artes marciais e, por outro lado, essas atividades e diversas outras, reafirmam e ajudam a produzir o senso de desordem que tanto buscam evitar. Na verdade, "a ação defensiva confere proximidade ao medo" (BAUMAN, 2007, p. 15), e esse medo ganha capacidade de se autoperpetuar e se auto-fortalecer.

Desse modo, a sociedade vive uma "dança de cadeiras ininterrupta", onde o progresso pressagia crise e tensão e impede o aumento do descanso. Os publicitários e a grande mídia exploram esse medo generalizado como principal fonte de capital (capital do medo) gerando, por meio da informação, ainda mais, insegurança no presente e incertezas quanto ao futuro; um novo individualismo, uma decadência da solidariedade e o afrouxamento dos laços sociais. Daí, o medo é visto como um demônio que é alimentado por meio dessas condições sociais impostas pela sociedade líquido-moderna. Esse demônio só será 
exorcizado quando encontrarmos, ou, mais precisamente, quando construirmos ferramentas políticas capazes de democratizar e permitir a equidade social. A informação pode ser um caminho para isto. Por outro lado, a modernidade líquida é a condição ideológica a partir da qual a pósverdade pode erguer-se como uma espécie de reação retrógrada.

\section{A INFORMAÇÃO NO COMBATE A PÓS-VERDADE}

Como podemos observar, as mudanças socioculturais apontadas por Bauman (2007) na sociedade atual parecem irrefreáveis. Segundo o autor, o esforço individual em busca da felicidade tem mudado as relações de solidariedade, afastando as pessoas que, privadas de uma rede de apoio, constroem um campo de temores disseminados de perigos generalizados, nem sempre com respaldo da realidade (BAUMAN, 2007). E, assim, a inconstância, a instabilidade e, sobretudo, o medo, fazem com que os usuários das redes sociais compartilhem informações incertas e controversas. Desse modo, a informação tem, nos dias atuais como em nenhum outro momento da história, o poder de transformação social, e deve ir à contramão dos discursos de ódio disseminados através das pósverdades.

Segundo González de Gómez (1999, p. 78):

a informação, independente do conceito a ela empregado, não é um elemento autônomo. Ela se caracteriza como um operador de relação, isto é, designa uma operação de caráter relacional, que se constitui da primeira vez num processo de experiência e de vivência e só realiza um valor semântico através de processos seletivos e interpretativos. É essa natureza relacional da informação que permite seja ela examinada como parte dos jogos culturais e sociais de produção de sentido, de seleção e de decisão.

Para a autora, a informação não é um elemento independente, muito pelo contrário, ela possui caráter relacional que se constitui de vivências e experiências, seleção e interpretação, fazendo, assim, parte dos jogos culturais e sociais de produção de sentido e decisão. Nas redes sociais, os usuários se utilizam da informação inserida nas fanpages para adaptá-las e propagá-las. Essa informação, que a todo o momento é 
transfigurada, pode mudar de significação e tornar-se um discurso da pósverdade. Segundo Dunker et al. (2017, p. 38):

alguns consideram que o discurso da pós-verdade corresponde a uma suspensão completa da referência a fatos e verificações objetivas, substituídas por opiniões tornadas verossímeis apenas à base de repetições, sem confirmação de fontes. Penso que o fenômeno é mais complexo que isso, pois ele envolve uma combinação calculada de observações corretas, interpretações plausíveis e fontes confiáveis em uma mistura que é, no conjunto, absolutamente falsa e interesseira.

O autor constata que o fenômeno da pós-verdade é complexo, pois envolve uma combinação de observações adequadas, interpretações plausíveis, fontes seguras, mas é em seu conjunto falsa e interesseira. Num momento onde emitir informação tornou-se um hábito e até mesmo uma compulsão,

o dogma que une todos em torno de Facebooks, Twittters, Instagrans, redes sociais que mudam de tempos em tempos numa avalanche de tecnologias descartáveis, sustenta-se como verdade ou como o que é considerado verdadeiro porque foi dito e apenas por isso (DUNKER et al., 2017, p. 114).

Sendo assim, as redes sociais são vistas como veículos de produção de exposição da verdade. Elas produzem e compartilham informações que, por sua vez, produzem dezenas de interpretações que podem ser propagadas reforçando ideias e estereótipos, influenciando nas tomadas de decisões e levando à alienação os sujeitos que a consomem. Essa relação entre informação e redes sociais, foi materializada em um estudo do Digital News Report (2016), do Reuters Institute, e revelou que mais da metade ( $51 \%)$ dos consumidores de 26 países usam as redes sociais como "fonte de notícias" pelo menos uma vez por semana. O mesmo estudo apontou, ainda, que cerca de $12 \%$ dos interrogados usam as redes sociais como sua "fonte principal" de notícias, e que o Facebook é de longe a "mais importante rede para encontrar, ler/ver e partilhar notícias". O Brasil, segundo o estudo, é um dos países mais ativos em mídias sociais no que diz respeito ao consumo de vídeos de notícias, atingindo 52\%, seguido de Grécia com 48\%. Quanto às mídias sociais, no Brasil, elas são 
usadas como fonte de notícias em aproximadamente $72 \%$ dos entrevistados da pesquisa (DIGITAL NEWS REPORT, 2016).

Por outro lado, há algo ainda mais espantoso: as redes sociais não são apenas importantes como "fontes de notícias", mas também são incentivadoras de discussões e compartilhamento de informação. E é, talvez, devido a esse aspecto que uma nova tendência tenha ganhado força: a pós-verdade. Deste modo, se a informação perpassa a ausência e a presença, se ela está nas palavras e nos silêncios (WILDEN, 1984), ela precisa ser/estar muito bem situada e apurada, para que sejam evitadas a formação e disseminação dessas pós-verdades.

Neste sentido, foca-se no conceito de Informação de Araújo (1998), que a considera como:

prática social de um sujeito cognitivo social que desenvolve ações de atribuição e comunicação de sentido que, por sua vez, podem provocar transformações nas estruturas (tanto individuais, como sociais), pois geram novos estados de conhecimento (ARAÚjO, 1998, p. 33).

Para o autor, a informação como prática social pode provocar transformações na estrutura social e individual da sociedade, por meio do conhecimento. E, por isso ela deve ser entendida como essencial no combate aos mais diversos fenômenos que visam destilar ódio, preconceito, discriminação, nas redes sociais, impondo uma memória de outrora, no contexto político-social-econômico atual, para promover mudanças comportamentais por meio de disseminação de informações difusas, saturada de crenças e apelos pessoais.

\section{CONSIDERAÇÕES FINAIS}

Analisando as mudanças socioculturais na sociedade através da ótica Baumaniana e correlacionando essas mudanças ao papel que a memória exerce, como constituinte do processo dos discursos e aos novos fenômenos de disseminação de pós-verdades, infere-se: a sociedade vem atravessando um momento de conflito, e a informação é elemento 
imprescindível na construção desse processo, portanto, deve ser produzida, utilizada e disseminada de maneira competente.

A mídia tem contribuído para instalar uma espécie de caos social. Isso é percebido nas redes sociais, através da ansiedade em emitir informações a todo custo, aumentando a descrença dos indivíduos quanto ao cenário político-social mundial por meio de pós-verdades, construídas com base nas memórias coletivas, apelos emocionais e crenças pessoais.

Considera-se que, ainda há muito a se discutir sobre memória, especialmente, memória coletiva e a dinâmica onde ela aflora, suas relações nas redes sociais e suas contribuições, de fato, quanto à formação de pós-verdades.

Percebe-se, através das reflexões sobre a modernidade líquida abordada por Bauman (2001), que a informação, mais que em nenhuma outra época, apresenta-se como elemento constituinte de emancipação, e, por que não dizer, evolução social. Portanto, sendo a informação elemento fundamental para emancipação política de um grupo/comunidade, estando sobre a égide do saber e do conhecimento, ela é imprescindível para o exercício da cidadania de maneira eficiente.

Por outro lado, não basta apenas ter o acesso material à informação, é preciso, sobretudo, ter a capacidade interpretativa da realidade em que a informação está inserida, especialmente, em tempos de pós-verdade, onde acontecimentos reais parecem ter menos importância que as deduções, crenças e suposições. Correlacionando as utopias das quais Bauman (2007) cita, com a informação como reguladora de processos emancipatório, afirma-se que é imprescindível tê-las. As utopias nos dão ânimo e a informação vivifica o saber e sem elas os homens ainda viveriam nas cavernas.

\section{REFERÊNCIAS}

ARAÚJO, E. A. A construção social da informação: práticas informacionais no contexto de Organizações Não-Governamentais/ ONGs brasileiras. 1998. 221f. Tese (Doutorado em Ciência da Informação e 
Documentação) - Faculdade de Estudos Sociais Aplicados, Universidade de Brasília, Brasília, 1998.

ASSMANN, A. Primeira parte: Funções. In: ASSMANN, A. Espaços de recordação: formas e transformações da memória cultural. Campinas: Unicamp, 2011. p. 15-160.

BAUMAN, Z. Tempos líquidos. Rio de Janeiro: Zahar, 2007.

BAUMAN, Z. Modernidade líquida. Rio de Janeiro: Zahar, 2001.

CARDINI, F. A memória coletiva no pensamento de M. Halbwachs. Conferência proferida no Instituto de Psicologia da Universidade de São Paulo em 10 de novembro de 1993.

DIGITAL NEWS REPORT. Reuters Institute for the Study of Journalism (RISJ). 2016.

DUNKER, C. et al. Ética e pós-verdade. Porto Alegre: Dublinense, 2017.

ELIAS, N. A sociedade dos indivíduos. Rio de Janeiro: Zahar, 1994.

FOUCAULT, M. Microfísica do poder. Rio de Janeiro: Graal, 2002.

GONZALEZ DE GOMES, M. N. O caráter seletivo das ações de informação. Informare, Rio de Janeiro, v. 5, n. 2, 1999. Disponível em: https://www.brapci.inf.br/index.php/article/view/0000004602 Acesso em: 25 jul. 2019.

HALBWACHS, M. A memória coletiva. Tradução de Beatriz Sidou. 2. ed. São Paulo: Centauro, 2013.

MAGALHÃES, M. D. B. A lógica da suspeição: sobre os aparelhos repressivos à época da ditadura militar no Brasil. Rev. bras. Hist., São Paulo, v. 17, n. 34, p. 203-220, 1997. Disponível em: http://www.scielo.br/scielo.php?script=sci arttext\&pid=S010201881997000200011\&lng=en\&nrm=iso Acesso em: 07 maio 2020.

OXFORD DICTIONARIES, 2018. Disponível em: https://www.lexico.com/definition/post-truth Acesso em: 06 out. 2019. Tradução pessoal.

SCHMIDT, M. L. S.; MAHFOUD, M. Halbwachs: memória coletiva e experiência. Psicologia USP, São Paulo, v. 4, n. 1-2, 1993. Disponível em: http://pepsic.bvsalud.org/scielo.php?script=sci_arttext\&pid=S1678$\underline{51771993000100013}$ Acesso em: 13 jul. 2018. 
WILDEN, A. Comunicação e cognição. Enciclopédia Einaudi. Lisboa: Imprensa Nacional - Casa da Moeda, 1984. 